\title{
Placebo i nocebo - psihijatrijski aspekti
}

\section{Placebo and nocebo - psychiatrist view}

\section{Milan Latas}

Klinika za psihijatriju UKCS, Medicinski fakultet, Beograd

Rad je referisan kao plenarno izlaganje na međunarodnom kongresu 16th BISOP koji je održan u Beogradu, 14. i 15. maja 2021. godine.

Primljeno 29. novembra 2021.; prihvaćeno 15. januara 2022. ; objavljeno na internetu 15.januara 2021. DOI: $10.5937 /$ engrami43-35138 


\section{Kratak sadržaj}

U radu je prikazan placebo i nocebo efekat koji se javlja u analgeziji sa osvrtom na to kako da se prepoznaju i razaznaju u kliničoj praksi uz prikaz nekih psihološko-psihijatrijskih elementa placebo i nocebo efekta. Definicija placebo analgezije podrazumeva umanjenje bola usled primene inertne supstance sa informacijom da supstanca efikasno ublažava bol. Za sada nije potpuno jasan mehanizam dejstva placeba, pa ni u analgeziji, ali se na osnovu brojnih istraživanja i velikog kliničkog iskustva pretpostavlja da postoje izvesni psihološki i psihijatrijski faktori koji se povezuju sa placebo efektom. S druge strane, nocebo efekt predstavlja mogućnost da se javi negativno uverenje i očekivanje koje prouzrokuje štetu, to jest loš efekt i šteta u organizmu. Dakle, nocebo predstavlja efekat negativnog očekivanja od tretmana. Na žalost, za razliku od istraživanja mehanizma nastanka placebo efekta, nije bilo istraživanja koja bi ukazala na psihološko/psihijatrijske mehanizme nastanka nocebo efekta. Sve u svemu, na osnovu velikog iskustva i na osnovu brojih studija koje su urađane može da se dođe do zaključka da se i placebo i nocebo sreću u svakodnevnoj lekarskoj praksi. Koliko će biti intenzivni zavisi od puno faktora. Zbog toga je važno da ih pravilno prepznamo i konrolišemo u radu s pacijentima. Dalja istraživanja mogu imati duboke implikacije za razumevanje ovih fenomena ali i na klinička ispitivanja i medicinsku praksu, kao i za farmakološke i psihosocijalne tretmane i intervencije.

\section{Ključne reči.}

Placebo, nocebo, psihijatrija, analgezija 


\section{Istorijat pojma placebo}

Reč placebo potiče od latinskog izraza placere, što znači svideti se, odnosno, udovoljiti, usrećiti. Pojam placebo se prvi put sreće u Biblijskim spisima u izrazu "Placebo Domino" što u prevodu znači udovoljiti Gospodu. Ovaj pojam se tada odnosio na hrišćanske vernike, posvećene religiji, koji veruju da udvoljavanjem Gospodu mogu sebi da obezbede miran i spokojan život na ovom i na onom svetu. Interesantno je da je pojam placebo upotrebljen i u 14. veku a odnosio se na osobe koje su prisustvovale sahranama kao ožalošćene osobe a da to, u stvari nisu bili tj., one osobe koje bi se pravile da žale i oplakuju preminulog za vreme sahrana, a kao naknadu bi dobijali hranu i piće. To je, zaprvo, značilo da su na lažan način sebi obezbeđivali neke priviligije. Međutim, u medicini se pojam placebo pojavljuje tek u drugoj polovini 18. veka u Novom Medicinskom Rečniku, opisujući pseudomedicinsku praksu koja teži da "udovolji" pacijentu umesto da ga izleči.

Placebo efekat se kao termin u svom današnjem značenju pojavljuje tokom Drugog svetskog rata. Naime, bostonski hirurg Bičer (Beecher) je, dok je boravio kao lekar na italijanskom ratištu, primetio da vojnici povređeni u ratu značajno manje trpe od svojih rana u odnosu na pacijente iz civilstva sa sličnim povredama u mirnodopskim uslovima [1]. On je tu pojavu objasnio time da su ranjeni vojnici kasnije pošteđeni od daljeg učestvovanja u ratnim operacijama, čime mogu da sačuvaju svoj život, za razliku od civila u mirnodopskim uslovima kojima povrede značano utiču na umanjen kvalitet budućeg života. Pored toga, on je primetio da se bolno osećaji ranjenih vojnika mogu umanjiti primenom najjednostavnijeg fiziološkog rastvora (umesto pravih analgetika) ali samo u situacijama kada ranjenici nisu upućeni u ovu "prevaru”. Naime, u odsustvu medikamenata u ratnim uslovima, on je ranjenim vojnicima aplikovao infuzije fiziološkog rastova uz napomenu da je to morfijim koji 
će da im umiri bolove. Rezultat je bio iznenađujuće povoljan jer su vojnici, u većini, zaista imali umanjenje bola kao rezultat terapije.

\section{Definicija placeba}

Danas je izraz placebo ušao u opštu primenu u medicini i odnosi se na specifičan efekat koji nastaje kada se pacijentu (ili subjektu u studiji) daje nektivan/lažan lek, odnosno, supstanca koja nema efikasno farmakološko dejstvo na organizam pri čemu pacijent nije upućen u detalje ove intrevencije, odnosno, on ostaje u uverenju da prima lekovito sredstvo [2]. Ova pojava se koristi najviše u istraživanjima novih lekovitih supstanci kada se istraživanje vrši na više grupa ispitanika:

- $\quad$ Kod jedne grupe ispitanika primenjuju se prave lekovite supstance a

- $\quad$ Kod druge grupe ispitanika primenjuju se supstance iste po obliku, boji i ukusu kao prve lekovite supstance ali koje nemaju farmakološki efekat, koji subjektima istraživanja nije poznat.

U analizi rezultata istraživanja kompariraju se efekti dejstva pravih lekovitih suspstanci i onih koje to nisu.

Definicija placebo analgezije podrazumeva umanjenje bola usled primene inertne supstance sa informacijom da supstanca efikasno ublažava bol [1].

\section{Mehanizam dejstva - kako deluje placebo?}


Za sada nije potpuno jasan mehanizam dejstva placeba, pa ni u analgeziji, ali se na osnovu brojnih istraživanja i velikog kliničkog iskustva pretpostavlja da postoje izvesni psihološki i psihijatrijski faktori koji se povezuju sa placebo efektom. Između ostalog, pokazalo se da je efekat placeba direktno povezan sa očekivanjem pacijenta [4]. Dakle, preduslov pojave placebo efekta je da pacijent ne zna da prima inertnu supstancu već da je uveren da prima stvarni lek. To znači da ako osoba očekuje pozitivan efekat supstance može da se dogodi da dođe do pozitivnog efekta samo na osnovu očekivanja. Pored toga, efekat očekivanja (a time i placebo efekat) može da se se pojača faktorima kao što su [5]:

- Postojanje razlika u izgledu tj., u boji i veličini pilula, što znači da se kod nekih pacijenata odrđena boja i izgled leka povezuje sa pozitivnim očekivanjem njegovog dejstva (i kao anegdota često se spominje promena forme leka Brufen ${ }^{\circledR}$ iz roze dražeje u belu tabletu, koja je uslovila slabije desjtvo kod nekih pacijenata),

- efekat „prvog utiska“ koji podrazumeva da učesnike placebo kontrolisane studije dočeka lekar/medicinska sestra u belom mantilu, umesto da ih dočeka devojka obučena u farmerke i običnu majcu, čime dobija osećaj ozbiljnosti i profesionalnosti a time i uspešosti tretmana ili

- korišćenje intervencija poput aplikacije injekcija umesto per os primene leka, uz uverenje da su injekcije delotvornije od tableta.

Crte ličnosti. Istraživanja pokazuju da su izvesne oobine ličnosti, koje su povezane sa dopaminergičkim funkcijama, povezane sa placebo analgetskim efektom [6]. Među njima se izdvajaju: a) traženje novina, b) izbegavanje štete i c) reakcija na nagrade [6]. To znači da su osobe sa više izraženim navedenim crtama ličnosti podložnije placebo efektu od onih kojima su ove crte ličnosti manje izražene. Pored toga, analiza crta ličnosti koje se detektuju NEO-P- 
R upitnikom ukazuju na određene osobine ličnosti koje su prediktori reakcije placeba na bol [6]: a) visoka ego-otpornost, b) visok NEO altruizam, c) visoka NEO usmerenost i d) niska NEO bes i ljutnja. To znači da osobe koje imaju navedenu kombinaciju crta ličnosti detektovanu NEO PI-R upitnikom pokazuju veći stepen reagovanja na placebo.

Teorije učenja. Pored izvesnih osobina ličnosti koje se povezuju sa placebo efektom, smatra se i da učenje može da ima značajan uticaj na placebo efekat. Naime, određene teorije učenja ukazuju da su inertne supstance, koje su se prethodno povezivale sa efikasnim lečenjem, takođe sposobne da generišu placebo efekte kroz postupke učenja [7]. Tako, na primer, teorija učenja po tipu klasičnog uslovljavanja ukazuje da postoji povezanost uslovne i bezuslovne draži. To znači da ukoliko je pacijent primio lek koji je pored željenog dejstva (na primer, analgezija - bezulovna draž) imao i sporedni efekat (na primer, osećaj žarenja u ustima kada popije lek - uslovna draž) u sledećoj situaciji kada bude uzeo neki lek koji uslovljava osećaj žarenja u ustima kada popije lek može da se javi i osećaj umanjenja bola/analgezija po principima klasičnog uslovljavanja. Pored toga, mehanizam učenja po tipu opservacije može da uslovi pojavu placebo efekta [8]. Naime, posmatranje drugih pacijenata kojima određeni lek pomaže (na primer, analgetsko delovanje) može da uslovi pojavu placebo efekta, tj., da i taj pacijent doživi isti efekat leka (na primer, analgetsko delovanje) koji je primetio i kod drugih pacijenata. Na kraju, postoji spekulacija i da operantno uslovljavanje može da bude odgovorno za pojavu placebo efekta [9]. Naime, operantno uslovljavanje podrazumeva učenje na osnovu posledica. Na primer, ako je lek pacijentu jednom pomogao i umanjio simptome (na primer bol) pacijent ima očekivanje (koje uslovljava placebo efekat) da će taj isti lek ponovo da mu pomogne kada ga bude uzeo.

\section{Šta je problem s placebom?}


Pored povoljnih efekata koji pokazuje placebo, postoje i brojni negativni efekti koji mogu da se jave nakon njegove primene. Jedna od glavnih nepovoljnih karakteristika placeba je to što ne utiče na tok bolesti. Naime, poznato je da rezultat koji se postiže efektom placebo supstance dovodi do toga da se neki pacijenti u određenim periodima osećaju bez tegoba i bez bola ali da sam rezultat dejstva placeba ne remeti značajno tok bolesti [10]. To znači da je umanjenje simptoma koje je postignuto placebo efektom samo privremeno i da se može se koristiti samo kratokoročno za umanjenje simptoma, ali ono ne može da bude dugoročno jer se, praktično, ne može koristiti za otklanjanje uzroka bolesti tj., kao prava terapija bolesti.

Drugi problem s placebom, pored toga što ne utiče na tok bolesti, je taj što ima ograničeno trajanje [10]. Između ostalog postojalo je uverenje da je lečenje placebom idealno za „umišljene bolesnike“ tj., za osobe obolele od hipohondrije. Međutim, i to se efakat placeba pokazao kao kratoktrajan i ne kao pouzdano sredstvo na koje se lekar može osloniti u terapiji hipohondrije.

Treći problem u primeni placebo efekta je nepredvidivost. Naime, pokazalo se da je efekt placebo terapije vrlo teško reproduktivati i vrlo je neizvesno kako će pacijent reagovati na primenu placeba [10]. To znači da neki ljudi iako imaju informaciju da dobijaju placebo umesto leka, ipak, ponekada imaju intenzivno uspešnu placebo reakciju, dok drugi ljudi koji iamju uverenje da primaju pravi lek, ipak, ne dobijaju očekivan pozitivan rezultat.

Na kraju se postavlja pitanje: Ako placebo može donekle da leči čoveka tj., da mu povremeno umanji simptome, kako možemo da procenimo kakav je objektivan rezultat primene leka? Jedini mogući odgovor na ovu dilemu je da moramo da radimo puno istraživanja koja bi poredila efikasnost lekovite supstance u odnosu prema placebo efektima jer tek na taj način možemo da dođemo do pravilnog odgovora, uz saznanje da se u savremenoj medicinskoj 
praksi efekat placeba ne može često koristiti, bar ne kao uspešno terapijsko sredstvo te da je, zbog kratkotrajnosti i nepredvidivosti, sistematična primena placeba praktično nemoguća.

\section{Definicija pojma nocebo}

Dakle, efekat placeba može da utiče na uverenje pacijenta da će mu biti bolje - ukoliko on veruje da će lek koji uzima može da pomogne, on će verovatno biti uspešan u lečenju, ali ako veruje da će da pravi problem ili štetu, lek može da prouzrokuje loše efekte, što je poznato kao nocebo efekat. Najjednostavniji primer je kada pacijent čita sve informacije o neželjenim efektima leka, uz uverenje da će mu se dogoditi ovakvi neželjeni efekti, vrlo verovatno i može da ih oseti i počinje da ih oseća.

Nocebo efekt predstavlja sposobnost negativnog uverenja i predosećaja koje pouzrokuje štetu, to jest loš rezultat u organizmu, odnosno, nocebo predstavlja efekat negativnog očekivanja od tretmana. [11]. Sinonimi su negativan placebo efekat, placebo neželjena reakcija, placebom indukovana nuspojava, negativan placebo odgovor i antiplacebo. A da bi se razumeo pojam noceba, koji je suprotan pojmu placeba, najbolje je prikazati primer. Tako je učesnicima u jednom istraživanju ukazano da će doživeti neprijatnu draž, tj. da će da im puštaju električnu energiju niskog intenziteta kroz glavu i da to može da izazove bol u glavi. [12]. Tokom istraživanja subjektima nije bila puštena električna energija a, ipak, više od polovine ispitanika je prijavilo da je dobilo bol u glavi. Ili, u drugoj studiji je grupi pacijenata data zašećerna voda uz informaciju da je to supstanca koja izaziva povraćanje. Po završenom eksperimentu $80 \%$ grupe je povraćalo šećernu vodu [12]. 


\section{Efekat noceba}

Nocebo je prisutan i u realnim uslovima medicinske prakse. Većini praktičara je već poznato da intenzivnija negativna percepcija terapije kod pacijenta uslovljava jači nocebo odgovor tj. manji odgovor na terapiju i veći broj prijavljenih sporednih efekata. U praksi se najčešće sreće primer da se pacijent informiše o neželjenim efektima terapije koju očekuje da će da prima ili je već počeo prima (najčešće na internetu) i nakon toga počinje da veruje da su isti ti neželjeni efekti prisutni i kod njega [11]. Tako, fenomen noceba se može manifestovati u dva oblika: u specifičnom obliku kada pojedinac očekuje određeni/specifičan negativan ishod i taj ishod posledično nastaje, i u opštem obliku kada je pojedinac difuzno pesimističan i ima nejasna negativna očekivanja [13].

Na žalost, za razliku od istraživanja mehanizma nastanka placebo efekta, nije bilo istraživanja koja bi ukazala na psihološko/psihijatrijske mehanizme nastanka nocebo efekta. Ipak postoje faktori koje se povezuju sa većim intenzitetom nocebo efekta. Ovi faktori rizika mogu se klasifikovati kao karaktristike lekara, karakteristike pacijenata, faktori u vezi sa lekovima, karakteristike zdravstvenog okruženja i faktori povezani sa procesom bolesti [6]. Među njima, interakcija između pacijenta i lekara u vreme pregleda i terapije ima najveći katalitički uticaj na razvoj nocebo efekata. Nocebo utiče na pacijente svih uzrasta, ali nedavna metaanaliza ukazuje na to da su žene podložnije od muškaraca [14]. Pored toga, pacijenti sa somatizacijom, depresijom i anksioznim poremećajima, hroničnim bolom, kognitivnim oštećenjem ili jezičkim barijerama imaju veću predispoziciju za pojavu nocebo efekta [15]. Istorija štetnih efekata prethodnog lečenja i oscilirajući tok bolesti sa neuspehom u više linija terapije rezultira negativnim uslovljavanjem, što takođe dovodi do nocebo efekata [15].

Zbog toga su potrebna dalja istraživanja da bi se razumeli psihološki prediktori nocebo efekata koji potencijalno omogućavaju predviđanje nespecifičnih neželjenih efekata vezano 
za primenu neke terapije. Ipak, utisak je da efekt placeba može da bude uspešan od trećine do polovine slučajeva a da je nocebo efekt primetan u neverovatnih 55\% do čak $100 \%$ ispitanika [16]. Ovo sugeriše da smo, kao ljudska bića, mnogo više podložniji negativnoj sugestiji i nocebo efektu za razliku od pozitivne sugestije i placebo efekta [17]. To znači da je istinita sentenca: „Ako verujem da šteti, onda sigurno i šteti!““

\section{Zaključak}

Svaki medicinski ili psihosocijalni tretman ima dva sastavna faktora koji se odnose s jedne strane, na specifične efekte tretmana i, s druge starne, koji se odnosi na kontekst lečenja, individualnu percepciju, subjektivno značenje i psihološki odgovor. Sve u svemu, na osnovu velikog iskustva i na osnovu brojih studija koje su urađane može da se dođe do zaključka da se i placebo i nocebo sreću u svakodnevnoj lekarskoj praksi. Koliko će biti intenzivni zavisi od puno faktora a u upotrebnom smislu placebo može da bude dobar sluga a nocebo može da bude zao gospodar. Zbog toga je važno da ih pravilno prepoznamo i konrolišemo u radu s pacijentima. Dalja istraživanja mogu imati duboke implikacije za razumevanje ovih fenomena ali i na klinička ispitivanja i medicinsku praksu, kao i za farmakološke i psihosocijalne tretmane i intervencije.

\section{Izjava o sukobu interesa.}

Autor izjavljuje da nema sukoba interesa 


\section{Literatura}

1 Beecher HK. The powerful placebo. J Am Med Assoc. 1955; 159:1602-6

2 Merriam-Webster.com. 2011. https://www.merriam-webster.com (28.12.2021)

3 Benedetti F. Mechanisms of placebo and placebo-related effects across diseases and treatments. Ann. Rev. Pharmacol. Toxicol. 2008; 48(33):60.

4 Brown WA. Expectation, the placebo effect and the response to treatment. R I Med J (2013). 2015 May 1;98(5):19-21. PMID: 25938400

5 Meissner K, Linde K. Are Blue Pills Better Than Green? How Treatment Features Modulate Placebo Effects. Int Rev Neurobiol. 2018;139:357-378. doi:

10.1016/bs.irn.2018.07.014. Epub 2018 Aug 6. PMID: 30146054.

6 Peciña M, Azhar H, Love TM, Lu T, Fredrickson BL, Stohler CS, Zubieta JK. Personality trait predictors of placebo analgesia and neurobiological correlates.

Neuropsychopharmacology. 2013;38(4):639-46.

7 Bajcar EA, Bąbel P. How Does Observational Learning Produce Placebo Effects? A Model Integrating Research Findings. Front Psychol. 2018; 24;9:2041.

8 Bajcar EA, Wiercioch-Kuzianik K, Farley D, Adamczyk WM, Buglewicz E, Bąbel P. One of us or one of them? The effects of the model's and observer's characteristics on placebo analgesia induced by observational learning. PLoS One. 2020 Dec 16;15(12):e0243996.

9 Bąbel P. Operant conditioning as a new mechanism of placebo effects. Eur J Pain. 2020; 24(5):902-908. 
10 Klinger R, Stuhlreyer J, Schwartz M, Schmitz J, Colloca L. Clinical Use of Placebo Effects in Patients With Pain Disorders. Int Rev Neurobiol. 2018;139:107-128.

11 Slomski A. "Important Conversations" Are Needed to Explain the Nocebo Effect. JAMA. 2021; 325(8):707-9.

12 Colloca L, Miller FG. The nocebo effect and its relevance for clinical practice. Psychosom Med. 2011;73(7):598-603

13 Hahn RA. The nocebo phenomenon: scope and foundations. In: Harrington, A. (Ed.), The Placebo Effect—An Interdisciplinary Exploration. Harvard University Press, 2000; 56-76.

14 Vambheim SM, Flaten MA. A systematic review of sex differences in the placebo and the nocebo effect. J Pain Res 2017; 10:1831-9.

15 Amanzio M, Palermo S, Skyt I, Vase L. Lessons Learned From Nocebo Effects in Clinical Trials for Pain Conditions and Neurodegenerative Disorders. J Clin Psychopharmacol 2016; 36(5):475-82.

16 Jakovljevic M. The placebo-nocebo response: controversies and challenges from clinical and research perspective. Eur Neuropsychopharmacol. 2014; 24(3):333-41.

17 Milovanović S, Ćulafić Đ, Šer F. Placebo efekat. Engrami, 1996; 18:131-9. 


\begin{abstract}
The paper presents the placebo and nocebo effects that occur in analgesia with a review of way how to recognize them in clinical practice and with the presentation of some psychological and psychiatric elements of the placebo and nocebo effects in clinical practice. The definition of placebo in analgesia implies the reduction of pain due to the use of an inert substance with the information that the substance effectively relieves pain. For now, the mechanism of action of placebo is not completely clear, even in analgesia, but based on numerous studies and extensive clinical experience, it is assumed that there are certain psychological and psychiatric factors that are associated with the placebo effect. On the other hand, the nocebo effect represents the ability of negative beliefs and expectations that cause harm/a negative effect in the body. Thus, nocebo represents the effect of negative expectations from treatment. Unfortunately, there was no research that would indicate the psychological / psychiatric mechanisms of the nocebo effect i clinical practice. Overall, based on extensive experience and based on a number of studies that have been done, it can be concluded that both placebo and nocebo meet in everyday medical practice. How intense it will be depends on many factors. That is why it is important to properly recognize and control them when working with patients. Further research may have profound implications for understanding these phenomena.
\end{abstract}

\title{
Key words.
}

Placebo, nocebo, psychiatry, analgesia 